J. Med. Microbiol. - Vol. 25 (1988), 191-196

(C) 1988 The Pathological Society of Great Britain and Ireland

\title{
Mucosal association by Clostridium difficile in the hamster gastrointestinal tract
}

\author{
S.P. BORRIELLO, A. R. WELCH, FIONA E. BARCLAY and HEATHER A. DAVIES* \\ Microbial Pathogenicity Research Group, Division of Communicable Diseases, and *Electron Microscopy \\ Research Group, Clinical Research Centre, Watford Road, Harrow, Middlesex HA1 3UJ
}

\begin{abstract}
Summary. For many organisms, mucosal association is an important virulence determinant. Although studied in detail for other intestinal pathogens, this aspect of pathogenicity has not been studied for Clostridium difficile. We compared the ability of an avirulent non-toxigenic strain (M-1), a highly virulent toxigenic strain (B-1), and a poorly virulent toxigenic strain (BAT) of $C$. difficile to adhere to different regions of the gastrointestinal tract of hamsters pre-treated with clindamycin. Strain B-1 associated with the gut mucosa significantly better than strain $M-1(p<0.001)$ for all sites other than the caecum, and achieved significantly higher levels in the caecal contents $(\mathrm{p}<0 \cdot 001)$. The same was true when strain B-1 was compared with strain BAT except that there was no significant difference for the large bowel mucosa. To assess the possible role of toxin in promoting mucosal association, e.g., by compromising host defences or exposing masked adherence sites, strain M-1 was given to animals after intra-caecal administration of crude toxin preparations from strain B-1, which were heat-inactivated in control experiments. The addition of this toxin increased significantly the mucosal association of $\mathrm{M}-\mathrm{l}$ for the small bowel only, whereas the inactivated toxin had no significant effect. These results imply that there may be intrinsic differences between strains in their ability to colonise and associate with the gut mucosa, which may partly depend on their ability to produce toxin. These differences do not correlate with cell-surface hydrophobicity or the presence of plasmids, flagella or fimbriae.
\end{abstract}

\section{Introduction}

Clostridium difficile is firmly implicated as the cause of pseudomembranous colitis and some cases of antibiotic-associated and sporadic diarrhoea (Borriello, 1984). Although the role of the two major toxins of $C$. difficile, toxins $\mathrm{A}$ and $\mathrm{B}$, has been established in the pathogenesis of the disease (Lyerly et al., 1985; Mitchell et al., 1986, 1987; Ketley et al., 1987) not all toxigenic strains cause disease (Borriello et al., 1987) and asymptomatic carriage has been documented in all age groups (Larson et al., 1982; Libby et al., 1983; Bender et al., 1986; Peach et al., 1986). Several host factors such as the degree of colonisation resistance exerted by the normal gut flora (Borriello and Barclay, 1984) or the expression of toxin-binding sites at colonic cell surfaces (Krivan et al., 1986) may contribute to the spectrum of disease seen in man (Burdon, 1984; Borriello et al., 1985). Recently we have demonstrated that not all toxigenic strains of

Received 16 April 1987; accepted 30 May 1987.
C. difficile are equally virulent in the Syrian hamster model of antibiotic-associated colitis (Borriello et $a l ., 1987)$. These differences in virulence correlated with the ability to colonise the gut efficiently and with the levels of toxin A produced in vivo (Borriello et al., 1987). The ability of bacteria to adhere to gastrointestinal cell surfaces is becoming recognised increasingly as a prerequisite for colonisation of the gut (Hartley et al., 1979) and expression of virulence (Lancet, 1977; Cheney et al., 1980; Boedeker, 1982). Because this potential virulence determinant had not been investigated for $C$. difficile, we compared the ability of a highly virulent toxigenic strain, a poorly virulent toxigenic strain and an avirulent non-toxigenic strain of $C$. difficile to associate with the mucosa at different sites within the gastrointestinal tract of the Syrian hamster. Further, we examined the effect of crude preparations of mixtures of toxins $A$ and $B$ on the adherence exhibited by the non-toxigenic strain. Factors that could account for adherence, e.g., flagella, fimbriae, or plasmids which may code for an adherence factor, were also investigated. 


\section{Materials and methods}

\section{Source and identification of $C$. difficile strains}

Strain B-1, toxigenic and highly virulent, was isolated from a patient with pseudomembranous colitis (Borriello et al., 1987); strain BAT, toxigenic but poorly virulent, was isolated from the ward environment of a neonatal unit (Borriello et al., 1987); and strain M-1, non-toxigenic and avirulent, was isolated from a patient with Shigella sonnei diarrhoea (Borriello and Barclay, 1985). Isolates were identified as described by Borriello et al. (1987).

\section{Preparation of inocula for animal experiments}

Starter cultures of $C$. difficile were prepared by inoculating $20 \mathrm{ml}$ of pre-reduced Brain Heart Infusion Broth (Difco) containing L-cysteine $\mathrm{HCl} 0.05 \% \mathrm{w} / \mathrm{v}$ and sodium formaldehyde sulphoxylate $0.03 \% \mathrm{w} / \mathrm{v}$ as reducing agents (BHI broth) with a colony of $C$. difficile taken directly from a blood-agar purity plate and incubating anaerobically for $48 \mathrm{~h}$. The cultures were centrifuged at $4500 \mathrm{rpm}$ at $4^{\circ} \mathrm{C}$ for $15 \mathrm{~min}$; the pellet was resuspended and centrifuged twice in $20-\mathrm{ml}$ volumes of fresh BHI broth. The final pellet was suspended in fresh BHI broth to give an opacity equal to a Wellcome opacity tube No. 8 and the number of colony forming units $(\mathrm{cfu}) / \mathrm{ml}$ was determined in duplicate. This yielded a suspension of $c$. $10^{8} \mathrm{cfu} / \mathrm{ml}$ which was used as the oral inoculum for the animal experiments.

\section{Isolation of C. difficile from animal material}

Isolation of $C$. difficile and an estimate of the mean cfu of caecal content were performed in duplicate by the micromethod described previously (Borriello and Barclay, 1986). Briefly, this consisted of simultaneous dilution of up to eight specimens in a microtitration tray and seeding on cycloserine-cefoxitin selective agar. Isolation and quantitation from segments of gastrointestinal tract were performed as follows. The whole of the gastrointestinal tract was removed from killed animals and placed in a sterile petri-dish. A portion about $6 \mathrm{~cm}$ long of jejunum, starting from the proximal end, and of ileum and colon starting from the distal end, and the whole of the caecum, were excised and cut longitudinally to expose the contents and inner surface. The open segments were washed in a mixture of equal volumes of BHI broth and saline (BHIS) with a pasteur pipette to remove the bulk of the contents and the washed segments were transferred individually to $10 \mathrm{ml}$ of BHIS in a $28-\mathrm{ml} \mathrm{screw-capped}$ glass container and washed by repeated inversion. The procedure of transfer to fresh BHIS and washing was repeated ten times. Pilot studies had demonstrated that this was the minimum number of washes required to remove regularly non-adherent bacteria. Washed tissue was weighed and suspended in BHIS to yield a 1 in 10 dilution ( $w / v)$ and homogenised in sterile glass tissue grinders. Ten-fold dilutions $(w / v)$ of caecal contents were also prepared in BHIS. The mean $C$. difficile $\mathrm{cfu} / \mathrm{g}$ of tissue was estimated in duplicate by the micromethod described by Borriello and Barclay (1986).

\section{Animals}

Adult Syrian hamsters (Mesocricetus auratus) weighing 150-200 g supplied from the National Institute for Medical Research, were used in all experiments. Each was inoculated intraperitoneally (i.p.) with $0.5 \mathrm{ml}$ of a solution of clindamycin phosphate (Dalacin C; Upjohn, Crawley, West Sussex) $10 \mathrm{mg} / \mathrm{ml}$ and housed individually in filter-lidded isolator cages (Techniplast animal cages; Biotech Consultants Ltd, Clackmannanshire, Scotland). Cages, food, water bottles and bedding were autoclaved in sealed bags before use. All animals received $0.5 \mathrm{ml}$ of the prepared $C$. difficile suspension per os (p.o.) between 10 and 20 days after clindamycin. This period was to allow for clearance of antibiotic. All animals were killed $24 \mathrm{~h}$ after receiving $C$. difficile. The following groups of animals were used:

Group 1. Ten animals were challenged 20 days after receiving clindamycin with the highly virulent toxigenic C. difficile strain B-1.

Group 2. Thirteen animals were challenged 20 days after receiving clindamycin with the poorly virulent toxigenic $C$. difficile strain BAT.

Group 3. Ten animals were challenged 11 days after receiving clindamycin with the avirulent non-toxigenic C. difficile strain $\mathrm{M}-1$.

Group 4. Ten animals were inoculated intra-caecally (i.c.), 15 days after receiving clindamycin, with $0.5 \mathrm{ml}$ of crude broth-culture filtrate of strain B-1 (48-h growth) adjusted by dilution in BHI broth to give a final cytotoxin titre of $10^{3}$. These animals were then challenged with strain M-1.

Group 5. Ten animals were treated in the same way as group- 4 animals with the exception that the crude toxin preparation to be given i.c. was first heated to $56^{\circ} \mathrm{C}$ for 30 min to inactivate $C$. difficile toxins $\mathbf{A}$ and $\mathbf{B}$.

\section{Animal surgery}

Animals were anaesthetised by i.p. injection of $0.5 \mathrm{ml}$ of an anaesthetic cocktail of water, Hypnorm (Janssen Pharmaceuticals) and Hypnovel (Roche Products Ltd) in a ratio of $2: 1: 1$. The abdomen was opened by a mid-line incision and the caecum exposed. After i.c. injection of relevant material for animals in groups 4 and 5 above, the wound was closed with catgut sutures for the peritoneum and silk sutures for the skin and occluded with a plastic skin spray (Opsite ${ }^{\circledR} ;$ Smith and Nephew).

\section{Determination of bacterial hydrophobicity}

Bacterial cell-surface hydrophobicity was determined by the method of Ljungh and Wadström (1982) based on precipitation of cells by ammonium sulphate (Lindahl et al., 1981) as modified by Borriello et al. (1987). 


\section{Determination of bacterial motility}

Motility was determined by phase-contrast microscopy of 20- $\mu \mathrm{l}$ samples of 18 -h $\mathrm{BHI}$ broth cultures of $C$. difficile. In addition Bacto-SIM (Sulphide-Indole-Motility) medium (Difco) was inoculated from a 72-h culture from Columbia Blood Agar (Oxoid), incubated anaerobically at $37^{\circ} \mathrm{C}$ for up to 5 days and examined for evidence of motility. For both methods, C. beijerinckii NCIB 9362 and $C$. perfringens strain F1726 (Food Hygiene Laboratory, PHLS, Colindale) were used as positive and negative controls respectively.

\section{Detection of plasmids}

The three strains of $C$. difficile were screened for plasmids by two methods (Birnboim and Doly, 1979; Hayter and Dale, 1984). Agarose gel electrophoresis was performed with a Minigel apparatus (Bio-Rad Laboratories).

\section{Examination for flagella and fimbriae}

C. difficile cells present in 24-h BHI-broth cultures were examined by negative staining for flagella as described by Fontaine et al. (1984). The presence of fimbriae was assessed on cells from the leading edge of growth of 48-h colonies on Columbia Blood Agar by a modification of the method of Henrichsen and Blom (1975) as described by Johnson and Davies (1984). Grids were examined in a Jeol 1200EX electron microscope.

\section{Statistical analysis}

The numbers of $C$. difficile (cfu/g) in tissue from each anatomical site sampled and in the caecal contents of the different groups were compared with each other by an algorithm described by Hill and Peto (1971). This permutation test resembles Wilcoxon's test but deals with the observations themselves instead of their ranks and gives exact results even in the presence of large numbers of ties.

\section{Results}

The results of caecal colonisation and association with the mucosa of different regions of the gastrointestinal tract are compared in table I. Those comparisons yielding significant differences are presented in table II. Differences in the ability to associate with the gut mucosa were most noticeable in the small bowel. The toxigenic, poorly virulent strain BAT adhered to gut mucosa and colonised the caecal contents to the same extent as the nontoxigenic, avirulent strain M-1. Neither of these strains associated with gut mucosa or colonised the caecal contents as well as the virulent, toxigenic strain B-1 (table II). The presence of $C$. difficile toxins (toxins A and B) increased the degree of mucosal association exhibited by strain M-1 significantly and resulted in levels of association similar to those found for the toxigenic strain B-1 (table II). The co-administration of heat-inactivated toxins had no such effect.

Strains B-1 and BAT had multiple flagella and were motile, whereas strain M-1 was non-flagellate and non-motile. The motility seen was of a twitching-tumbling type, unlike that of the 'rapid gliding' type seen with $C$. beijerinckii. None of the strains had plasmids or possessed fimbriae. No differences in hydrophobicity were seen which might explain the observed differences in mucosal association; all strains were hydrophilic with cells aggregating over the range $2-3 \mathrm{M}\left(\mathrm{NH}_{4}\right)_{2} \mathrm{SO}_{4}$.

Table I. Colonisation of hamsters by different strains of $C$. difficile

\begin{tabular}{|c|c|c|c|c|c|c|c|c|c|c|c|}
\hline \multirow{3}{*}{$\begin{array}{l}\text { Experimental } \\
\text { group }\end{array}$} & \multirow{3}{*}{$\begin{array}{l}\text { Number of } \\
\text { animals }\end{array}$} & \multicolumn{10}{|c|}{ Number of animals colonised (n) and mean (range) $\log _{10} \mathrm{cfu}$ in } \\
\hline & & \multicolumn{2}{|c|}{ jejunum } & \multicolumn{2}{|r|}{ ileum } & \multicolumn{2}{|r|}{ caecum } & \multicolumn{2}{|r|}{ colon } & \multicolumn{2}{|c|}{ caecal contents } \\
\hline & & $\mathrm{n}$ & $\mathrm{cfu}$ & $\mathrm{n}$ & $\mathrm{cfu}$ & $\mathrm{n}$ & $\mathrm{cfu}$ & $\mathrm{n}$ & $\mathrm{cfu}$ & $\mathrm{n}$ & cfu \\
\hline 1. Strain B-1 & 10 & 10 & $\begin{array}{c}4 \cdot 3 \\
(3 \cdot 0-5 \cdot 0)\end{array}$ & 10 & $\begin{array}{c}4 \cdot 7 \\
(3 \cdot 0-5 \cdot 3)\end{array}$ & 10 & $\begin{array}{c}5 \cdot 4 \\
(3 \cdot 8-5 \cdot 9)\end{array}$ & 10 & $\begin{array}{c}5 \cdot 5 \\
(3 \cdot 8-6 \cdot 5)\end{array}$ & 10 & $\begin{array}{c}8 \cdot 5 \\
(6 \cdot 3-8 \cdot 8)\end{array}$ \\
\hline 2. Strain BAT & 13 & 2 & $\begin{array}{c}3 \cdot 9 \\
(3 \cdot 5-4 \cdot 3)\end{array}$ & 3 & $\begin{array}{c}3 \cdot 4 \\
(3 \cdot 0-4 \cdot 0)\end{array}$ & 11 & $\begin{array}{c}4 \cdot 7 \\
(3 \cdot 5-5 \cdot 9)\end{array}$ & 10 & $\begin{array}{c}4 \cdot 5 \\
(3 \cdot 0-5 \cdot 8)\end{array}$ & 13 & $\begin{array}{c}6 \cdot 2 \\
(2 \cdot 7-8 \cdot 2)\end{array}$ \\
\hline 3. Strain M-1 & 10 & 1 & $3 \cdot 3$ & 1 & 3.7 & 6 & $\begin{array}{c}4 \cdot 4 \\
(3 \cdot 5-5 \cdot 6)\end{array}$ & 5 & $\begin{array}{c}4 \cdot 1 \\
(3 \cdot 3-4 \cdot 8)\end{array}$ & 10 & $\begin{array}{c}5 \cdot 5 \\
(3 \cdot 3-8 \cdot 4)\end{array}$ \\
\hline $\begin{array}{l}\text { 4. Strain } M-1+\text { intracaecal } \\
\text { toxin }\end{array}$ & 10 & 5 & $\begin{array}{c}4 \cdot 0 \\
(3 \cdot 3-4 \cdot 8)\end{array}$ & 8 & $\begin{array}{c}4 \cdot 4 \\
(3 \cdot 3-6 \cdot 8)\end{array}$ & 8 & $\begin{array}{c}4 \cdot 5 \\
(3 \cdot 3-5 \cdot 7)\end{array}$ & 5 & $\begin{array}{c}4 \cdot 6 \\
(3 \cdot 3-5 \cdot 5)\end{array}$ & 8 & $\begin{array}{c}6 \cdot 9 \\
(5 \cdot 7-8 \cdot 1)\end{array}$ \\
\hline $\begin{array}{l}\text { 5. Strain } M-1+\text { intracaecal } \\
\text { heat-inactivated toxin }\end{array}$ & 10 & 2 & $\begin{array}{c}4 \cdot 0 \\
(3 \cdot 6-4 \cdot 4)\end{array}$ & 4 & $\begin{array}{c}4 \cdot 8 \\
(3 \cdot 3-5 \cdot 8)\end{array}$ & 6 & $\begin{array}{c}4.9 \\
(3 \cdot 0-6 \cdot 4)\end{array}$ & 5 & $\begin{array}{c}4 \cdot 4 \\
(3 \cdot 3-6 \cdot 3)\end{array}$ & 10 & $\begin{array}{c}4 \cdot 8 \\
(3 \cdot 0-8 \cdot 6)\end{array}$ \\
\hline
\end{tabular}


Table II. Significant differences between strains of $C$. difficile for colonisation of hamster gastrointestinal tract

\begin{tabular}{|c|c|c|c|c|c|}
\hline \multirow[b]{2}{*}{ C. difficile strains compared } & \multicolumn{4}{|c|}{$\begin{array}{l}\text { Significance of differences ( } p \text { values) in adherence of } \\
\text { strains to }\end{array}$} & \multirow{2}{*}{$\begin{array}{l}\text { Differences in colon- } \\
\text { isation of caecal } \\
\text { contents ( } p \text { values) }\end{array}$} \\
\hline & jejunum & ileum & caecum & colon & \\
\hline \multirow{4}{*}{$\begin{array}{l}\text { Virulent strain B-1 } v \text { s toxigenic poorly virulent } \\
\text { strain BAT } \\
\text { Virulent strain B-1 } v \text { s non-toxigenic avirulent } \\
\text { strain M-1 } \\
\text { Virulent strain B-1 } v \text { s non-toxigenic avirulent } \\
\text { strain M-1 administered with toxin } \\
\text { Non-toxigenic avirulent strain M-1 } v s \text { same strain } \\
\text { administered with toxin }\end{array}$} & $<0.001$ & $<0.001$ & NS & 0.05 & $<0.001$ \\
\hline & $<0.001$ & $<0.001$ & 0.02 & $<0.001$ & $<0.001$ \\
\hline & NS & NS & NS & 0.02 & $0 \cdot 04$ \\
\hline & $0 \cdot 04$ & $<0.001$ & NS & NS & NS \\
\hline
\end{tabular}

$\mathrm{NS}=$ not significant

\section{Discussion}

This study clearly shows that strains of $C$. difficile differ significantly in their ability to colonise the hamster gastrointestinal tract both on mucosal surfaces and in caecal luminal contents. The findings confirm our earlier observation that the poorly virulent, toxigenic strain BAT colonises less efficiently than the highly virulent strain B-1, and the proposal that this difference may reflect differences in the ability to associate with the gut mucosa (Borriello et al., 1987).

The present findings indicate that $C$. difficile toxins may be involved in the promotion of mucosal association, because the co-administration of crude preparations of $C$. difficile toxins with a nontoxigenic strain resulted in a significantly greater adherence to small bowel mucosa comparable to that of the toxigenic strain B-1. It is unlikely that the increase in mucosal association was due to the operative procedures used which could have helped to promote adherence, e.g., by a decrease in small bowel peristalsis, because no such effect was noted in experiments where heat-inactivated crude toxin preparations were used. It is possible, however, that there may have been other heat-labile products present that were involved in enhancing mucosal association. The possible role of toxins in promoting mucosal association is also supported by the observations that the poorly virulent, toxigenic strain BAT, which is known to produce low levels of toxins in vitro, and in vivo over the first few days of infection (Borriello et al., 1987), associated with gut mucosa poorly compared to the more toxigenic, virulent counterpart strain B-1. In fact, strain BAT behaved like the non-toxigenic strain in this respect. These findings are similar to those with Vibrio cholerae, in which cholera toxin appears to enhance mucosal association in the small bowel (Pierce $e t$ al., 1985). How these toxins promote colonisation is unknown. It is possible that the toxins of $C$. difficile expose masked receptor sites as a consequence of cell damage, that they change cell surface charge, or that the toxins compromise the host's ability to limit adherence, e.g., by reducing peristalsis or affecting mucosal secretion. Whatever the mechanism it does appear that toxin production confers a colonisation advantage. Additional evidence for this is provided by the findings of Borriello and Barclay (1985) who showed that in hamsters colonised with a non-toxigenic strain of $C$. difficile (strain M-1) and subsequently challenged with a toxigenic strain (strain B-1), the latter eventually became the dominant of the two, which suggests the ability to produce toxin may confer some ecological advantage. There is some evidence that this may also be true for Escherichia coli in pigs (Hinton et al., 1985) and to a lesser extent for Yersinia enterocolitica in man (Pai et al., 1978).

The mechanism by which $C$. difficile adheres to the gut is unknown. Although we have since shown that some strains do produce fimbriae (Borriello, Barclay and Davies, unpublished observations) none of the strains used in these experiments possessed them. It is unlikely that adherence was mediated by a flagellum-associated adhesin such as is found in Campylobacter jejuni (Newell et al., 1985) because the non-toxigenic strain that lacked flagella adhered as well as the poorly virulent, toxigenic strain which was flagellate. Furthermore, the non-toxigenic, non-flagellate strain adhered to small bowel as well as the virulent, toxigenic, flagellate strain when toxins were co-administered. 
The factors contributing to the full expression of virulence of $C$. difficile are complex. Virulence inevitably depends on the determinants possessed by $C$. difficile and the extent to which the host environment allows them to be expressed. From this point of view, the degree of colonisation resistance afforded by the normal gut flora probably plays a greater role in $C$. difficile infection than with other intestinal pathogens. It would appear that toxin production promotes mucosal association at some sites in the gastrointestinal tract and that this may lead to successful colonisation. Production of

\section{REFERENCES}

Bender B S et al., 1986 Is Clostridium difficile endemic in chroniccare facilities? Lancet 2: 11-13.

Birnboim H C, Doly J 1979 A rapid alkaline extraction procedure for screening recombinant plasmid DNA. Nucleic Acid Research 7: 1513-1523.

Boedeker E C 1982 Enterocyte adherence of Escherichia coli: its relation to diarrheal disease. Gastroenterology 83: 489-492.

Borriello S P (ed) 1984 Antibiotic-associated diarrhoea and colitis: the role of Clostridium difficile in gastro-intestinal disorders. Martinus Nijhoff Publishers, The Hague.

Borriello S P, Barclay F E 1984 Colonization resistance to Clostridium difficile infection. Microecology and Therapy 14 : 75-87.

Borriello S P, Barclay F E 1985 Protection of hamsters against Clostridium difficile ileocaecitis by prior colonisation with non-pathogenic strains. Journal of Medical Microbiology 19 : 339-350.

Borriello S P, Barclay F E 1986 An in-vitro model of colonisation resistance to Clostridium difficile infection. Journal of Medical Microbiology 21 : 299-309.

Borriello S P et al. 1985 Host and microbial determinants of the spectrum of Clostridium difficile mediated gastrointestinal disorders. Microecology and Therapy 15: 231-236.

Borriello S P et al. 1987 Clostridium difficile-a spectrum of virulence and analysis of putative virulence determinants in the hamster model of antibiotic-associated colitis. Journal of Medical Microbiology 24 : 53-64.

Burdon D W 1984 Spectrum of disease. In: Borriello S P (ed) Antibiotic-associated diarrhoea and colitis: the role of Clostridium difficile in gastrointestinal disorders. Martinus Nijhoff Publishers, The Hague, p.9.

Cheney C P, Schad P A, Formal S B, Boedeker E C 1980 Species specificity of in-vitro Escherichia coli adherence to host intestinal cell membranes and its correlation with in-vivo colonization and infectivity. Infection and Immunity 28: 1019-1027.

Fontaine E A R, Borriello S P, Taylor-Robinson D, Davies H A 1984 Characteristics of a gram-negative anaerobe isolated from men with non-gonococcal urethritis. Journal of Medical Microbiology 17: 129-140.

Hartley C L, Neumann C S, Richmond M H 1979 Adhesion of commensal bacteria to the large intestine wall in humans. Infection and Immunity 23: 128-132.

Hayter P M, Dale J W 1984 Detection of plasmids in clinical isolates of Clostridium difficile. Microbios Letters 27: 151156. toxin by adherent cells would result in toxin release close to its site of action, thus promoting adjacent mucosal association and localised toxin production. This whole process would be further enhanced if the strain of $C$. difficile exhibited chemotaxis towards mucosal receptors. We are currently examining this possibility.

We thank Dr I. D. Hill for statistical advice and analysis.

More detailed analysis of strain M-1 has demonstrated that a few cells possessed flagella. This type of finding has been noted by others (Dr P. N. Levett, personal communication).

Henrichsen J, Blom J 1975 Correlation between twitching motility and possession of polar fimbriae in Acinetobacter calcoaceticus. Acta Pathologica et Microbiologica Scandinavica 83 (Section B) : 103-115.

Hill I D, Peto R 1971 Probabilities derived from finite populations. Applied Statistics 20: 99-105.

Hinton M, Hampson D J, Hampson E, Linton A H 1985 A comparison of the ecology of Escherichia coli in the intestine of healthy unweaned pigs and pigs after weaning. Journal of Applied Bacteriology 58: 471-478.

Johnson A P, Davies H A 1984 Demonstration by electron microscopy of pili on Gardnerella vaginalis. British Journal of Venereal Diseases 60: 396-397.

Ketley J M, Mitchell T J, Candy D C A, Burdon D W, Stephen J 1987 The effects of Clostridium difficile crude toxins and toxin A on ileal and colonic loops in immune and nonimmune rabbits. Journal of Medical Microbiology 24: 4152.

Krivan H C, Clark G F, Smith D F, Wilkins T D 1986 Cell surface binding site for Clostridium difficile enterotoxin: evidence for a glycoconjugate containing the sequence Gal $\alpha 1-3 \mathrm{Gal} \beta 1-4 \mathrm{Glc}$ NAc. Infection and Immunity 53: 573581.

Lancet 1977 Bacterial adhesiveness and the gut. Lancet 1 : 12931294.

Larson H E, Barclay F E, Honour P, Hill I D 1982 Epidemiology of Clostridium difficile in infants. Journal of Infectious Diseases 146: 727-733.

Libby J M, Donta S T, Wilkins T D 1983 Clostridium difficile toxin A in infants. Journal of Infectious Diseases 148: 606.

Lindahl M, Faris A, Wadström T, Hjertén S 1981 A new test based on 'salting out' to measure relative surface hydrophobicity of bacterial cells. Biochimica et Biophysica Acta 677 : 471-476.

Ljungh A, Wadström T 1982 Salt aggregation test for measuring cell surface hydrophobicity of urinary Escherichia coli. European Journal of Clinical Microbiology 1 : 388-393.

Lyerly D M, Saum K E, MacDonald D K, Wilkins T D 1985 Effects of Clostridium difficile toxins given intragastrically to animals. Infection and Immunity 47:349-352.

Mitchell T J, Ketley J M, Burdon D W, Candy D C A, Stephen J 1987 Biological mode of action of Clostridium difficile toxin A : a novel enterotoxin. Journal of Medical Microbiology. 23: 211-219.

Mitchell T J et al. 1986 Effect of toxin A and toxin B of Clostridium difficile on rabbit ileum and colon. Gut 27: 7885. 
Newell D G, McBride H, Dolby J M 1985 Investigations on the role of flagella in the colonization of infant mice with Campylobacter jejuni and attachment of Campylobacter jejuni to human epithelial cell lines. Journal of Hygiene 95 : 217-227.

Pai C H, Mors V, Toma S 1978 Prevalence of enterotoxigenicity in human and nonhuman isolates of Yersinia enterocolitica. Infection and Immunity 22 : 334-338.
Peach S L, Borriello S P, Gaya H, Barclay F E, Welch A R 1986 Asymptomatic carriage of Clostridium difficile in patients with cystic fibrosis. Journal of Clinical Pathology 39: 10131018.

Pierce N F, Kaper J B, Mekalanos J J, Cray W C 1985 Role of cholera toxin in enteric colonization by Vibrio cholerae $\mathrm{O} 1$ in rabbits. Infection and Immunity 50: 813-816. 